\title{
Caracterização fenotípica e genotípica de caracteres agronômicos em uma população de linhagens recombinantes de aveia (Avena sativa $\mathbf{L}$.)
}

\author{
Phenotypic and genotypic characterization agronomic traits in a population of recombinant \\ inbred lines of oats (Avena sativa L.)
}

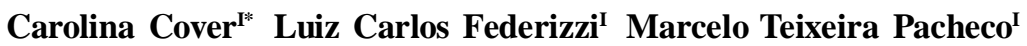

RESUMO

O melhoramento genético de aveia envolve a seleção de múltiplos caracteres quantitativos e qualitativos. $O$ conhecimento das regiões genômicas que afetam essas características possibilita a seleção assistida por marcadores moleculares. Nesse sentido, o objetivo deste trabalho foi identificar regiões genômicas responsáveis por caracteres quantitativos (QTLs), associadas a marcadores moleculares previamente identificados. $O$ experimento foi conduzido no ano de 2009, sendo empregadas 150 linhagens recombinantes de aveia, oriundas do cruzamento entre os genótipos UFRGS 8 e UFRGS 930605. O mapeamento de QTLs foi realizado através do método por intervalo composto. Foram detectados 16 QTLs para oito dos 9 caracteres avaliados, sendo estes distribuídos em sete grupos de ligação. A porção da variação fenotípica explicada pelos QTLs variou de 7,31\% a 16,06\%. Importantes QTLs foram identificados para caracteres de interesse aos programas de melhoramento de aveia, como a estatura de planta, o número de dias ao florescimento, o rendimento de grãos, o peso de panícula e o número de grãos por panícula. Os resultados gerados neste trabalho fornecem subsídios aos programas de melhoramento genético de aveia, proporcionando um maior entendimento dos mecanismos genéticos envolvidos com os caracteres de interesse. No entanto, estes resultados devem ser validados em outras populações para que a seleção assistida por marcadores moleculares possa ser realizada com sucesso.

Palavras-chave: Avena sativa L., locos de características quantitativas, marcadores moleculares.

\section{ABSTRACT}

The genetic improvement of oats requires selection of multiple quantitative and qualitative traits. Knowledge of the genomic regions controlling them makes possible the adoption of marker-assisted selection. Therefore, the objective of this study was to identify genomic regions responsible for quantitative traits loci (QTLs) associated with molecular maker previously identified. The experiment was conducted in 2009 and employed a population of 150 recombinant inbred lines of oats from the cross between the oat genotypes UFRGS 8 and UFRGS 930605. QTL mapping was carried out by composite interval analysis. In all, 16 QTLs were detected for 8 of 9 traits analyzed, which were also distributed in seven linkage groups. Phenotypic variation explained by the QTLs ranged from $7.31 \%$ to $16.06 \%$. QTLs with important effect on the phenotypic variance were identified for traits of interest in oat breeding programs, such as plant height, number of days to flowering, grain yield, panicle weight and number of grains per panicle. The results generated in this work provide a better understanding of the genetic basis controlling traits of interest, which can be useful for oat breeding programs. However, these results should be validated in other populations in order to allow the markerassisted selection to be successful.

Key words: Avena sativa L., quantitative trait loci, molecular markers.

\section{INTRODUÇÃO}

No Sul do Brasil, a aveia (Avena sativa L.) é uma das principais culturas utilizadas, resultado do intenso melhoramento genético da cultura, que determinou a introdução desta no sistema de semeadura direta. Até a década de 80 , as principais variedades de aveia cultivadas eram provenientes dos Estados Unidos ou Argentina, e apresentavam problemas de adaptação ao ambiente brasileiro,

IFaculdade de Agronomia, Departamento de Plantas de Lavoura, Universidade Federal do Rio Grande do Sul (UFRGS), 91501-970, Porto Alegre, RS, Brasil. E-mail: carolinacover@gmail.com. *Autor para correspondência. 
principalmente por apresentarem um longo ciclo de cultivo e uma elevada estatura, o que resultava no acamamento de plantas, no baixo rendimento de grãos e na baixa qualidade do produto (FEDERIZZI \& PACHECO, 2009). Assim, para que a cultura pudesse se inserir no sistema de produção, foi necessária uma mudança drástica nos principais caracteres adaptativos. O número de dias ao florescimento é um dos caracteres modificados que merece maior destaque, já que o número de dias da semeadura à colheita foi reduzido de 190 para menos de 130 dias (FEDERIZZI \& PACHECO, 2009). A estatura de planta foi outro caráter que sofreu forte pressão de seleção, sendo estimada uma redução de $31 \%$ ou $1,60 \mathrm{~cm}$ ano ${ }^{-1}$, ao comparar variedades antigas e modernas (BARBOSA NETO et al.,1996).

Em relação ao rendimento de grãos, foram obtidos ganhos na ordem $44 \mathrm{~kg} \mathrm{ha}^{-1} \mathrm{ano}^{-1}$, ou $22 \% \mathrm{em}$ 40 anos (BARBOSA NETO et al., 2000). Como o rendimento em aveia é resultado da combinação de diversos componentes, como a produção de fitomassa, o peso de panícula, o número de grãos, a estatura de planta, e a precocidade de ciclo, o que se busca é a modificação desses caracteres individuais e a combinação destes num ideotipo de planta visando a aumentar o potencial de rendimento (PELTONENSAINIO, 1990).

Apesar dos avanços obtidos, ainda existem oportunidades para melhorar a eficiência dos programas de melhoramento de aveia. Dentre as ferramentas da genética molecular, os mapas genéticos têm se revelado como um recurso de grande valor, pois permitem a localização de genes ou locos responsáveis por características quantitativas (QTLs). O conhecimento das regiões genômicas que afetam essas características possibilita a seleção assistida por marcadores moleculares (MAS - Marker Assited Selection), técnica que visa a complementar a seleção convencional, permitindo a seleção indireta de caracteres que apresentam dificuldade de avaliação ou que são altamente afetados pelo ambiente.

Em aveia, vários QTLs e marcadores associados têm sido identificados para diferentes caracteres (BOTHONA et al., 1997ab; HOLLAND et al., 2002; KOEYER et al., 2004; WOOTEN et al., 2009). Apesar dos vários trabalhos, são poucos os realizados em populações brasileiras, sendo assim necessário que estudos sejam conduzidos nos genótipos adaptados ao Sul do Brasil. No ano de 2007, linhagens recombinantes de aveia, resultantes do cruzamento entre os genótipos UFRGS 8 e UFRGS 930605 (U8 x U605), foram submetidas, pelo Programa de Melhoramento Genético de Aveia da UFRGS, para análise de marcadores DArT (Diversity Arrays Technology), sendo gerados nesta análise 177 marcadores moleculares. Com a disponibilidade desses marcadores moleculares, é possível a construção de mapas genéticos para a população oriunda do cruzamento, bem como se faz necessário identificar a cosegregação desses marcadores de DNA com as características fenotípicas de interesse. Sendo assim, o objetivo deste trabalho é de caracterizar, fenotipicamente e genotipicamente, linhagens recombinantes de aveia para os diferentes caracteres adaptativos e de rendimento de grãos da cultura.

\section{MATERIAL E MÉTODOS}

O experimento foi conduzido no ano de 2009 na Estação Experimental Agronômica da Universidade Federal do Rio Grande do Sul (EEA/UFRGS), em Eldorado do Sul, na região fisiográfica da Depressão Central do Rio Grande do Sul, a 3005'52" de latitude sul e 51³9'08' de longitude oeste, a uma altitude média de 46 metros acima do nível do mar. O clima da região é do tipo Cfa, segundo a classificação de Koeppen, com precipitação pluvial média anual de $1440 \mathrm{~mm}$ (BERGAMASCHI, 2003). O solo da área experimental pertence à unidade de mapeamento São Jerônimo, caracterizado como Argissolo Vermelho Distrófico típico (STRECK et al., 2002).

Neste estudo, foram avaliadas fenotipicamente 150 linhagens recombinantes F6 (RILs - Recombinant Inbred Lines), desenvolvidas através do cruzamento entre os genótipos U8 x U605. A população foi desenvolvida pelo método de SSD (Single Seed Descendent), sem seleção até a geração F5. O principal caráter que distingue os genótipos parentais se refere ao ciclo vegetativo. O genótipo U8 apresenta um gene maior para florescimento precoce, sendo insensível ao fotoperíodo (LOCATELLI et al., 2008). Já o genótipo U605 é dependente de dias longos para florescer, sendo considerado de ciclo semitardio (LOCATELLI et al., 2006).

O delineamento experimental foi de blocos casualizados com três repetições. Cada linhagem constituiu uma parcela de 5 linhas e $3 \mathrm{~m}$ de comprimento, com espaçamento de $0,2 \mathrm{~m}$ entre linhas. A semeadura, direta e mecanizada, foi realizada no dia três de julho, sendo utilizada uma densidade de 300 sementes $\mathrm{m}^{-2}$. A adubação de base constituiu de $300 \mathrm{~kg} \mathrm{ha}^{-1}$ da fórmula 10-30-15 de N-P-K. As sementes foram tratadas com o inseticida Imidacloprid, na dose de $60 \mathrm{ml} 100 \mathrm{~kg}$ de sementes $^{-1}$ do produto. A adubação de cobertura consistiu de duas doses de nitrogênio, na dose de $70 \mathrm{~kg}$ ha $^{-1}$ de uréia em cada aplicação. $O$ controle de plantas 
daninhas foi realizado através da aplicação do herbicida Metsulfurom-metílico, na dose de $4 \mathrm{~g} \mathrm{ha}^{-1}$. O controle da ferrugem da folha, causada por Puccinia coronata f. sp. avenae, foi realizado com a aplicação do fungicida Tebuconzole, na dose de $750 \mathrm{ml} \mathrm{ha}^{-1}$.

$\mathrm{O}$ vigor inicial (V) e densidade de plantas na parcela (D) foram avaliados visualmente, sendo atribuídas notas de um a cinco. Notas maiores de vigor foram atribuídas às parcelas em que as plantas apresentaram bom afilhamento, com boa produção de biomassa e notas menores para as parcelas em que as plantas apresentavam baixa produção de biomassa. A densidade foi avaliada como um critério que visava monitorar possíveis falhas de cada linhagem na parcela, já que parcelas sem falhas receberam nota cinco, sendo atribuídas notas decrescentes conforme os danos encontrados. O número de dias até o florescimento (NDF) foi considerado aquele em que $50 \%$ da parcela apresentava $50 \%$ da panícula do colmo principal exposta. A data inicial para o cálculo dos dias até o florescimento foi estabelecida como sendo o dia da semeadura. Após a plena floração, foi avaliado o número de colmos férteis (NCF) em um metro linear representativo da parcela. A estatura (E) de cada linhagem foi medida quando as plantas encontravamse próximas da maturação, correspondendo à distância entre o solo e a espigueta mais alta da planta. Para isso, foram tomadas três plantas ao acaso por parcela e em seguida feita a média. De cada parcela, foram separadas 10 panículas do colmo principal e, em laboratório, foram feitas as seguintes determinações: peso de panícula (PP), em gramas, número de espiguetas por panícula (NEP) e o número de grãos por panícula (NGP). O rendimento de grãos $(\mathrm{R})$ foi obtido através da massa de grãos, não desaristados, colhidos de forma mecanizada de cada parcela e transformados para $\mathrm{kg}$ $\mathrm{ha}^{-1}$. O peso do hectolitro $\left(\mathrm{kg} \mathrm{hL}^{-1}\right)$ foi obtido após o desaristamento e limpeza dos grãos colhidos de cada parcela. A partir dos grãos obtidos da panícula, foi realizada a avaliação de pilosidade dos grãos, sendo atribuídas notas de 1 a 3, utilizando-se o seguinte critério: 1- pouco piloso; 2- piloso e 3- muito piloso.

O mapa genético de ligação foi desenvolvido a partir de 177 marcadores DArT, identificados previamente por NAVA (2008), juntamente com 17 marcadores AFLP, desenvolvidos por LOCATELLI et al. (2006). O mapa foi desenvolvido com o programa JoinMap, versão 3.0 (OOIJEN \& VOORRIPS, 2001). Grupos de ligação foram identificados usando LOD (Logarithm of the odds) de 7,0. A máxima frequência de recombinação utilizada foi de $40 \%$ e as frequências de recombinação foram convertidas em distâncias genéticas (centiMorgans - cM) através da função
Kosambi. Para o mapeamento de QTLs, foram utilizadas as médias dos caracteres avaliados. Os valores fenotípicos foram utilizados para análise de mapeamento por intervalo composto (Composite Interval Mapping - CIM) pelo programa Windows QTL Cartographer ${ }^{\circledR}$ (WANG, 2007). O nível de significância de LOD para detectar QTLs foi de 2,5, com 1000 permutações e varredura de $2 \mathrm{cM}$ para análise. A estimativa da posição, efeito genético e porcentagem da variação fenotípica (dada pelo coeficiente de determinação, $\mathrm{R}^{2}$ ) dos QTLs foi estabelecida nos picos de LOD acima do nível de significância considerado.

\section{RESULTADOS E DISCUSSÃO}

A variabilidade genética na população pode ser verificada pela distribuição de frequências dos caracteres (Figura 1). A elevada amplitude de variação observada reflete o efeito do ambiente na expressão destes e também as diferenças genéticas entre as linhagens recombinantes. O caráter número de dias ao florescimento apresentou descontinuidade de distribuição e fez com que a população pudesse ser dividida em dois grupos, um com ciclo mais precoce, provavelmente sob a atuação do gene de insensibilidade ao fotoperíodo, oriundo do genótipo U8, e um com ciclo mais tardio (Figura 1).

O mapa molecular compreendeu 33 grupos de ligação (GL), cobrindo uma extensão total de $726,2 \mathrm{cM}$, valor considerado baixo se comparado a outros mapas, o que sugere uma menor diversidade molecular entre os genitores U8 e U605, quando comparado aos genitores de outros mapas desenvolvidos para a cultura. O primeiro mapa desenvolvido para a aveia cultivada, oriunda do cruzamento de A. byzantina C. Koch cv. 'Kanota' x A. sativa L. cv. 'Ogle' ( $\mathrm{K}$ x O) cobria uma distância de 1,482,0cM (O’DONOUGHUE et al., 1995). Já o mapa desenvolvido por ZHU \& KAEPPLER (2003), para uma população oriunda do cruzamento entre as cultivares Ogle x MAM17-5, cobre uma extensão de 1.396,7cM e possui 28 grupos de ligação.

Foram detectados, através do mapeamento por intervalo composto, 16 QTLs para 9 caracteres avaliados, sendo estes distribuídos em sete grupos de ligação (Tabela 1). A maioria dos QTLs apresentou valores de LOD score acima de 3,0, podendo ser considerados promissores na seleção assistida, já que este valor indica a confiabilidade da ligação entre QTL e marcador. A proporção da variação fenotípica explicada pelo conjunto de QTLs de cada caráter variou de $60,17 \%$ para a estatura de planta a $7,31 \%$ para o número de dias ao florescimento. Para o rendimento de 

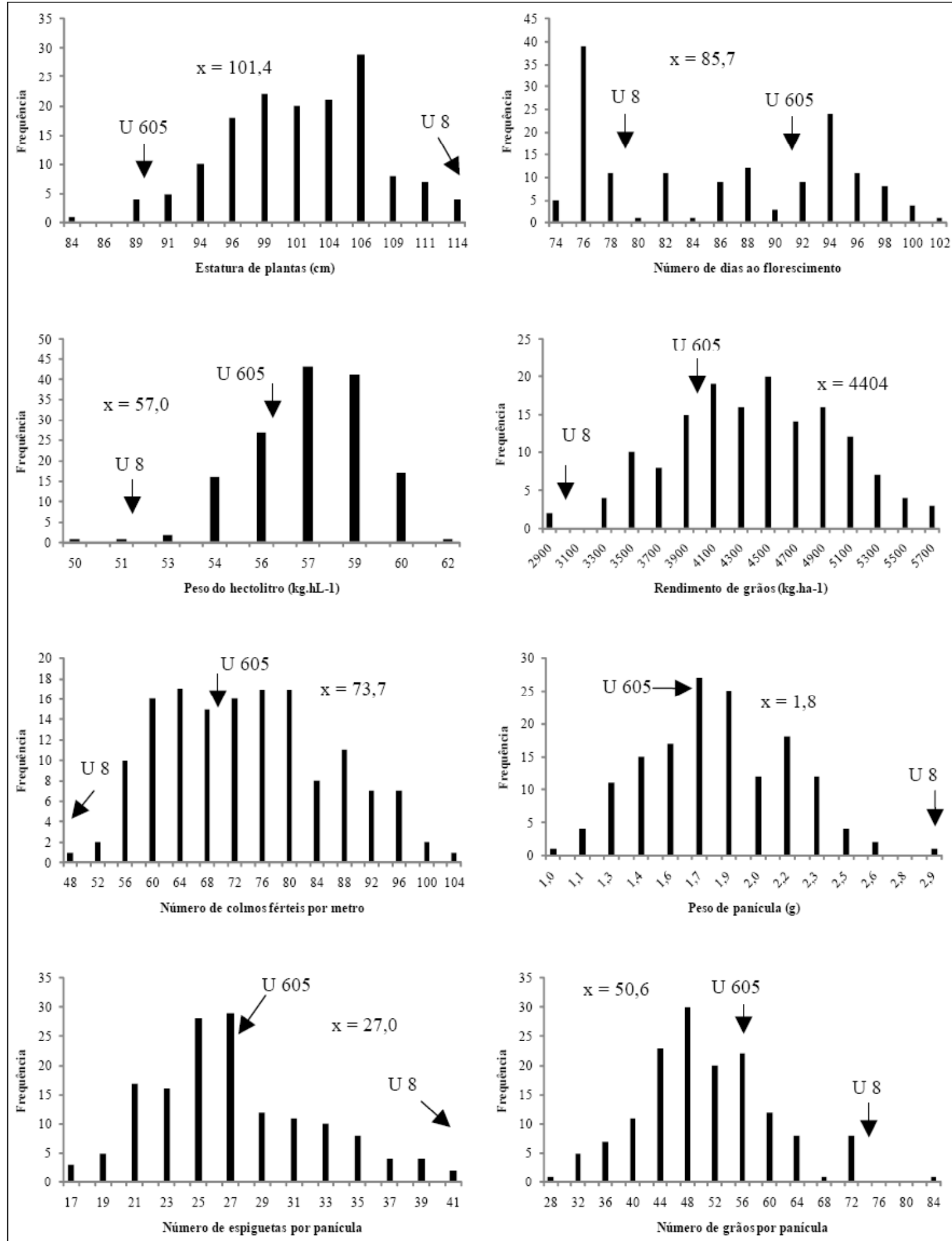

Figura 1 - Distribuição de frequências dos caracteres avaliados nas linhagens oriundas do cruzamento entre UFRGS 8 X UFRGS 930605. x = média da população. 
Tabela 1 - QTLs significativos detectados nas linhagens oriundas do cruzamento U8 X U605. E (estatura de planta), NDF (número de dias ao florescimento), PH (peso do hectolitro), R (rendimento), NCF (número de colmos férteis), PP (peso de panícula), NEP (número de espiguetas por panícula), NGP (número de grãos por panícula).

\begin{tabular}{|c|c|c|c|c|c|c|}
\hline Caráter & $\mathrm{GL}^{\mathrm{a}}$ & Marcador & Posição ${ }^{b}$ & LOD & Aditividade $^{\mathrm{c}}$ & $\mathrm{R}^{2}$ \\
\hline $\mathrm{E}$ & I & opt-16885_22.106 & 46,0 & 6,6 & 2,34 & 16,06 \\
\hline $\mathrm{E}$ & I & opt-14317_22.105 & 50,0 & 4,4 & 1,94 & 11,02 \\
\hline $\mathrm{E}$ & I & opt-17658_22.118 & 55,0 & 6,3 & 2,31 & 15,68 \\
\hline $\mathrm{E}$ & II & opt-7664_21.71 & 34,0 & 3,1 & 1,80 & 7,39 \\
\hline $\mathrm{E}$ & II & opt-8555_21.64 & 41,0 & 4,2 & 2,23 & 10,02 \\
\hline NDF & XII & opt-11481_16.21 & 4,0 & 2,5 & 2,40 & 7,31 \\
\hline PH & $\mathrm{V}$ & opt-15011 & 43,0 & 2,5 & 0,56 & 7,36 \\
\hline $\mathrm{R}$ & $\mathrm{V}$ & opt-13360 & 68,0 & 2,8 & $-204,43$ & 8,38 \\
\hline $\mathrm{R}$ & VIII & opt-14124 & 2,0 & 4,9 & 214,85 & 14,11 \\
\hline $\mathrm{NCF}$ & II & opt-18396_37.4 & 9,0 & 2,5 & $-3,96$ & 8,73 \\
\hline $\mathrm{NCF}$ & II & opt-10427 & 15,0 & 3,5 & $-4,25$ & 10,50 \\
\hline $\mathrm{NCF}$ & XVII & opt-1427_33.6 & 12,0 & 2,6 & 3,45 & 7,66 \\
\hline PP & VIII & opt-14189 & 12,0 & 3,0 & $-0,13$ & 7,62 \\
\hline PP & XI & opt-2978_19.32 & 4,0 & 3,1 & 0,14 & 8,36 \\
\hline NEP & XI & opt-2978_19.32 & 4,0 & 2,8 & 1,42 & 7,97 \\
\hline NGP & XI & opt-2978_19.32 & 4,0 & 4,0 & 3,14 & 11,29 \\
\hline
\end{tabular}

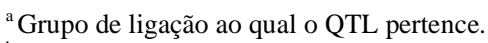

${ }^{\text {b }}$ Posição mais provável do QTL correspondendo ao pico de LOD, estimado pelo QTLCartographer®; distância em cM da primeira marca do grupo de ligação.

${ }^{\mathrm{c}}$ Efeito aditivo do QTL, estimado pelo QTLCartographer®.

grãos, principal componente econômico, a proporção da variação fenotípica explicada pelos dois QTLs detectados foi de 22,49\% (Tabela 1). Esses valores ressaltam o caráter quantitativo envolvido nas características avaliadas, pois revelam os QTLs de menor efeito.

Para o caráter estatura de plantas, foram detectados cinco QTLs, sendo que os alelos contribuem de forma positiva no caráter, aumentando a estatura de planta e são provenientes do genitor U8. Para o número de dias ao florescimento, foi detectado apenas um QTL. O alelo deste QTL possui efeito aditivo positivo, aumentando o ciclo da cultura em 2,4 dias, sendo este proveniente do genitor U605 (Tabela 1). Em trabalho realizado por NAVA (2008), foram encontrados QTLs para a característica de florescimento e de resposta à vernalização na população U8 x U605, entretanto, estas associações não foram detectadas no presente trabalho, o que pode ter decorrido dos diferentes ambientes nos quais a população foi fenotipada, o que reflete a interação dos QTLs com o ambiente, bem como podem ser explicados como sendo outras regiões genômicas influenciando o caráter.

Para os caracteres que compõem o rendimento de grãos, também foram detectados QTLs com efeito aditivo positivo, como o QTL para rendimento de grãos e o QTL para o número de colmos férteis, ambos provenientes do genitor U605. O QTL detectado associado aos caracteres peso de panícula, número de espiguetas por panícula e número de grãos por panícula, são provenientes do genótipo parental U8 (Tabela 1). QTLs para o peso de panícula são importantes, pois esse caráter inclui dois dos principais componentes do rendimento, o número de grãos e o peso de grãos por panícula, sendo, dessa forma, considerado um importante critério na seleção indireta de genótipos superiores de aveia. A detecção de QTLs que contribuem no aumento do rendimento de grãos em aveia é de grande importância aos programas de melhoramento da cultura, visto que esta é uma característica complexa, difícil de ser selecionada em gerações precoces. Sendo assim, esses QTLs devem ser validados em outras populações de forma a serem utilizados na seleção assistida por marcadores moleculares.

O marcador molecular opt-2978_19.32 foi encontrado associado aos caracteres peso de panícula, número de espiguetas e número de grãos por panícula (Tabela 1). Outros trabalhos identificaram em aveia regiões genômicas que influenciavam simultaneamente mais de uma característica, como, por exemplo, diferentes caracteres associados à qualidade dos grãos (GROH et al., 2001) e regiões associadas aos caracteres de estatura de planta e rendimento de grãos 
(ACHLEITNER et al., 2008). Esta mesma localização para diferentes caracteres tem sido explicada como o resultado de efeito pleiotrópico, porém a confirmação desse efeito apenas pode ser feita se houver clonagem do gene controlando os caracteres (SIRIPOONWIWAT et al.,1996; KOEYER et al., 2004).

\section{CONCLUSÃO}

Os resultados obtidos revelaram que é possível identificar QTLs com expressão no Sul do Brasil e esses, provavelmente, terão grande contribuição aos programas de melhoramento genético da cultura da aveia, permitindo a sua utilização na seleção assistida por marcadores moleculares. Porém, torna-se necessário que mais trabalhos sejam realizados para que sejam identificados novos QTLs que expliquem a maior parte da variação fenotípica dos caracteres de interesse. Além disso, mais marcadores devem ser adicionados ao mapa genético, para que, juntamente com a realização de novos experimentos de fenotipagem, com mais repetições e em diferentes ambientes, mais QTLs possam ser mapeados.

\section{REFERÊNCIAS}

ACHLEITNER, A. et al. Genetic diversity among oat varieties of worldwide origin and associations of AFLP markers with quantitative traits. Theoretical and Applied Genetics, Berlin, v.117, p.1041-1053, 2008. Disponível em: <http:// www.springerlink.com/content/r74021523n $35 \mathrm{t} 23 \mathrm{j} />$. Acesso em: 5 fev. 2010. doi: 10.1007/s00122-008-0843-y.

BARBOSA NETO, J.F. et al. Progressos em caracteres de importância agronômica em aveia. In: REUNIÃO DA COMISSÃO SULBRASILEIRA DE AVEIA, 16., 1996, Florianópolis. Resultados Experimentais. Florianópolis: Universidade Federal de Santa Catarina, 1996. p.98-101.

BARBOSA NETO, J.F. et al. Progresso genético no melhoramento da aveia-branca no Sul do Brasil. Pesquisa agropecuária brasileira, Brasília, v.35, n.8, p.1605-1612, 2000.

BERGAMASCHI, H. et al. Clima da Estação Experimental da UFRGS (e região de abrangência). Porto Alegre: UFRGS, 2003. 77p.

BOTHONA, C.R.A. et al. Identificação de QTLs para caracteres de importância agronômica em aveia expressos em quatro ambientes do sul do Brasil: I. ciclo e estatura de planta. In: REUNIÃO DA COMISSÃO SUL BRASILEIRA DE PESQUISA DE AVEIA, 17., 1997, Passo Fundo. Resumos... Passo Fundo: Universidade de Passo Fundo, 1997a. p.447-449.

BOTHONA, C.R.A. et al. Identificação de QTLs para caracteres de importância agronômica em aveia expressos em quatro ambientes do sul do Brasil: II. Comprimento e peso de panícula. In: REUNIÃO DA COMISSÃO SUL BRASILEIRA DE PESQUISA DE AVEIA, 17., 1997, Passo Fundo. Resumos... Passo Fundo: Universidade de Passo Fundo, 1997b. p.450-452.
FEDERIZZI, L.C.; PACHECO, M.P. Programa de melhoramento genético de aveia da UFRGS: 35 anos de história. In: REUNIÃO DA COMISSÃO BRASILEIRA DE PESQUISA DE AVEIA, 29., 2009, Porto Alegre. Resultados Experimentais... Porto Alegre: Universidade Federal do Rio Grande do Sul, 2009. p.202-205.

GROH, S. et al. Analysis of factors influencing milling yield and their association to other traits by QTL analysis in two hexaploid oat populations. Theoretical and Applied Genetics, Berlin, v.103, p.9-18, 2001. Disponível em: <http:/ /www.springerlink.com/content/tmh3 ca6y3gjrhekq/>. Acesso em: 9 jan. 2010. doi: 10.1007/s001220100579.

HOLLAND, J.B. et al. Genomic regions controlling vernalization and photoperiod responses in oat. Theoretical and Applied Genetics, Berlin, v.105, p.113-126, 2002. Disponível em: <http://www.ncbi.nlm.nih.gov/pubmed/ 12582569>. Acesso em: 24 set. 2009.

KOEYER, D.L. et al. A molecular linkage map with associated QTLs from a hulless $x$ covered spring oat population. Theoretical and Applied Genetics, Berlin, v.108, p.12851298, 2004. Disponível em: <http://www.ncbi.nlm.nih.gov/ pubmed/14767596>. Acesso em: 2 nov. 2009.

LOCATELLI, A.B. et al. Flowering time in oat: Genotype characterization for photoperiod and vernalization response. Field Crops Research, Wageningen, v.106, n.3, p.242-247, 2008. Disponível em: <http://www.sciencedirect.com/ science? ob = Article URL \& udi=B 6 T $6 \mathrm{M}$ 4 RR 211 F $1 \&$ \& user $=10 \&$ \& coverDate $=03 \% 2$ F $20 \% 2$ F2008\&_rdoc=1\&_fmt=high\&_orig=search\&_origin=search\&_sort=d \&_docanchor $=\& v i e w=c \& \_s e a r c h S t r I d=1627414771 \&$ rerunOrig in $=$ google \&_acct $=$ C000050221 \&_version $=1 \& \_u r l$ Version $=0 \&$ _userid $=10 \& m \mathrm{~m} 5=064 \mathrm{a} 60 \mathrm{febca} 8 \mathrm{ccdbaf} 8 \mathrm{f} 605 \mathrm{ad} 78 \mathrm{~d} 0 \mathrm{~b} 75 \&$ searchtype $=\mathrm{a}>$. Acesso em: 31 out. 2009. doi:10.1016/j.fcr.2007.12.006.

LOCATELLI, A.B. et al. Loci affecting flowering time in oat under short-day conditions. Genome, Ottawa, v.49, n.12, p.1528-1538, 2006. Disponível em: <http:// www.ncbi.nlm.nih.gov/pubmed/17426767>. Acesso em: 6 jun. 2009. doi: $10.1139 / \mathrm{G} 06-108$.

NAVA, I.C. Caracterização genética e molecular de fatores associados a resposta a vernalização para o florescimento em aveia. 2008. 117f. Tese (Doutorado em Fitotecnia, Plantas de Lavoura) - Programa de Pós-graduação em Fitotecnia, Faculdade de Agronomia, UFRGS, RS.

O'DONOUGHUE, L. et al. A molecular linkage map of cultivated oat. Genome, Ottawa v.38, p.368-380, 1995.

OOIJEN, J.W. VAN; VOORRIPS, R.E. JoinMap®. Software for the calculation of genetic linkage maps. Versão 3.0. Wageningen, 2001. Disponível em: <http://www.kyazma.nl/ index. php/mc.JoinMap>. Acesso em: 10 mar. 2010.

PELTONEN - SAINIO, P. Morphological and physiological characters behind high-yelding ability of oats (Avena sativa), and their implications for breeding. Field Crops Research, Amsterdam, v.25, p.247-252, 1990.

SIRIPOONWIWAT, W. et al. Chromosomal regions associated with quantitative traits in oat. Journal of quantitative trait loci, v.2, 1996. Disponível em: <http://wheat.pw.usda.gov/jag/ papers96/paper396/oatqt13g.html>. Acesso: 9 fev. 2010. 
STRECK, E.V. et al. Solos do Rio Grande do Sul. Porto Alegre: EMATER/RS / UFRGS, 2002. 127p.

WANG, S. Windows QTL Cartographer 2.5. (Software). Raleigh, NC: Department of Statistics, North Carolina State University, 2007. Disponível em: <http://statgen.ncsu.edu/ qtlcart/WQTLCart.htm>. Acesso em: 10 mar. 2010.

WOOTEN, D.R. et al. Quantitative trait loci and Epistasis for oat winter-hardiness component traits. Crop Science, Madison, v.49, p.1989-1998, 2009. Disponível em: <http:// w w w $4 . \mathrm{n} \mathrm{c} \mathrm{s} \mathrm{u} \mathrm{.} \mathrm{e} \mathrm{d} \mathrm{u} \mathrm{/} \mathrm{j} \mathrm{h} \mathrm{o} 11 \mathrm{and} / \mathrm{P}$ u b s / Wooten,DR.2009.QTLEpistasisoatwinterhardiness.CropSci.pdf $>$. Acesso em: 01 fev.2010. doi: 10.2135/cropsci2008.10.0612.

ZHU, S.; KAEPPLER, H.F. A genetic linkage map for hexaploid, cultivated oat (Avena sativa L.) based on an intraspecific cross Ogle/MAM17-5. Theoretical and Applied Genetics, Berlin, v.107, p.26-35, 2003. Disponível em: <http:// www.springerlink.com/content/v8vd0659b104muuf/>. Acesso em: 10 jan. 2010. doi: 10.1007/s00122-003-1191-6. 